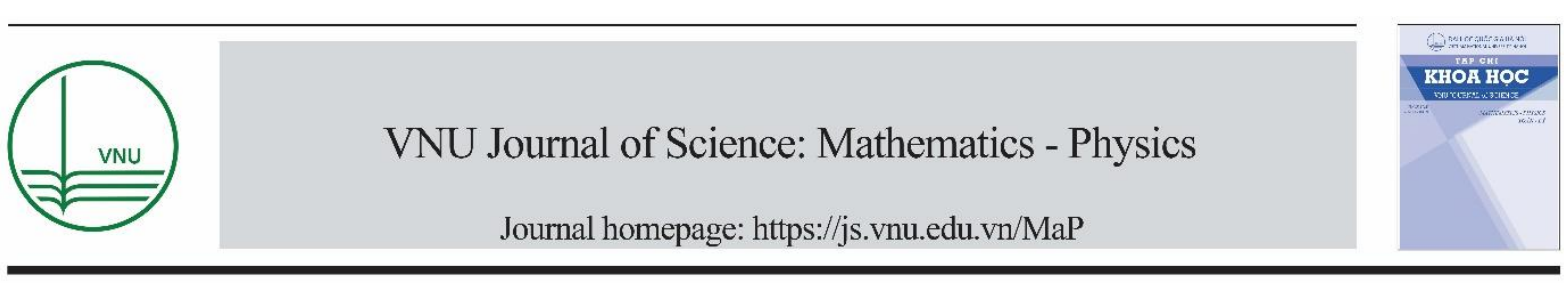

Original Article

\title{
Research, Design and Fabrication Microwave Modules of Receiver for NanoDragon Satellite at S Band
}

\author{
Bui Thi $\mathrm{Ha}^{1, *}$, Bach Gia Duong ${ }^{2}$ \\ ${ }^{I}$ Vietnam National Space Center, Viet Nam Academy of Science and Technology \\ ${ }^{2}$ University of Engineering and Technology, Vietnam National University, Hanoi, Vietnam
}

Received 6 March 2019

Revised 01 April 2019; Accepted 01 April 2019

\begin{abstract}
In the paper, the new microwave modules of NanoDragon satellite's receiver were designed and fabricated. Purpose of this design is not only reduce budget but also respond to frequency requirement, bandwidth and transmission rate. The microwave modules consist of low noise amplifier (LNA), mixer and local oscillator (LO). These modules operate at $\mathrm{S}$ band according to requirement of satellite. Firstly, each module was designed, simulated, fabricated and measured. Then they were integrated together. Output of integrated microwave modules is IF signal with bandwidth is suitable for demodulation PCM - PM (BPSK). And have high gain value conform to receiver's requirement. Simulation result of low noise amplifier is $19.108 \mathrm{~dB}$ at $2.9 \mathrm{GHZ}$. Simulation result of integrating two stage LNA become 2-stage LNA have gain value over $38 \mathrm{~dB}$. Gain value obtained is $11.5 \mathrm{~dB}$ when measurement. Integrating microwave modules result is $10.5 \mathrm{~dB}$ with gain value. That mean this microwave modules of receiver operated very well. LNA was very good. This subsystem can apply for NanoDragon satellite's receiver and receiver of ground station.

Keywords: Receiver, Microwave Modules of Receiver, Satellite, NanoDragon satellite, LNA, Mixer, LO, IF.
\end{abstract}

\section{Introduction}

Nowadays, space technology is become very popular. In space technology, satellite is one of most important. Satellite be used for weather forecasting, observation, exploration, radio and television broadcasting, salvaging and rescuing. One of the keys to success to such a mission is to have a stable and reliable receiver; without receiver, ground station is not able to receive data and control satellite,

\footnotetext{
*Corresponding author.

Email address: btha@vnsc.org.vn
}

https//doi.org/ 10.25073/2588-1124/vnumap.4330 
satellite is not able to receive command data from ground station. So design and manufacture receiver is necessary.

The results of this paper will be applied for NanoDragon satellite. NanoDragon Satellite weights approximately $10 \mathrm{Kg}$. The main missions of NanoDragon Satellite is capture pictures of Vietnam coast and tracking ship. Mission was shows in Figure 1. The system consists of a satellite named NanoDragon satellite and a ground station planned to locate in Hanoi, Vietnam. The NanoDragon satellite or the Space Segment plays a role of taking images by payload and afterwards transmit the images and telemetry (TLM) to the Ground Station or the Ground Segment. On the other hand, the Ground Station is to receive telemetry and images from the NanoDragon satellite and send commands (CMD) to the satellite as well.

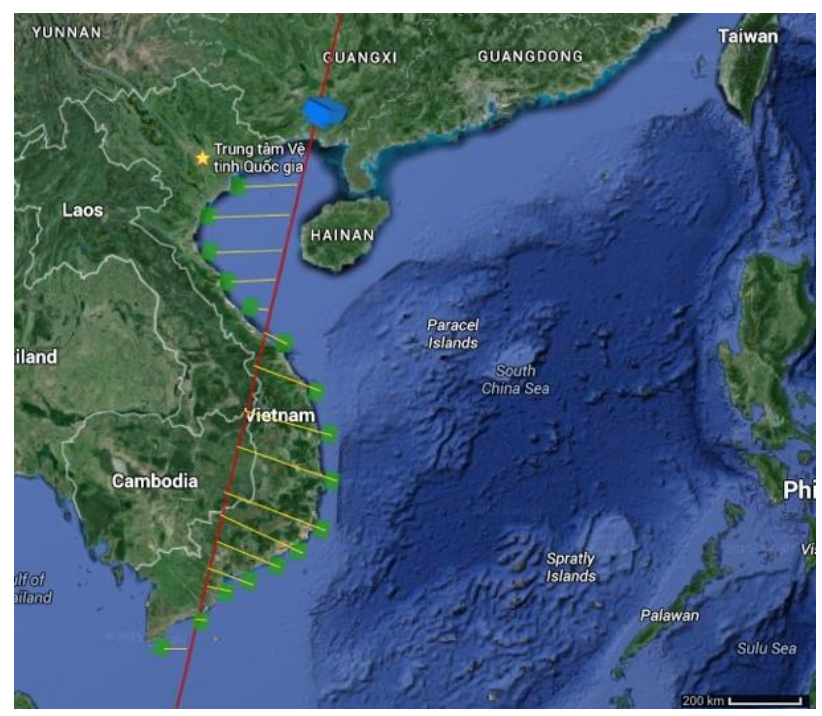

Figure 1. Mission of NDG.

Communication system provide link between Nanosatellite and ground station. It transmits telemetry data and payload data from satellite to ground station; tele-command data from ground station to satellite. NDG Satellite will capture pictures of Vietnam coast and store at memory. When NDG go through ground station, the satellite will change its attitude to direct S-band to ground side for transmitting TLM and receiving CMD. After creating connection, pictures data will be transmitted from satellite to ground station. That mean, telemetry data and tele-command data are implemented through S-band RF signal. Payload data downlink through X-band.

Detail requirement for communication is:

Be able to send $876 \mathrm{MB}$ of mission data (Data Capability Analysis) to ground station everyday with $10 \mathrm{Mbps}$ required bit rate. So, need a high speed X - band downlink data.

Be able to send Telemetry from the satellite to the ground station in a different live with mission data's and with the bit rate is from 4 kbps to $64 \mathrm{kbps}$ (following the quality of the link between satellite side and Ground side). So, need a $\mathrm{S}$ band downlink for telemetry.

Be able to receive commands from the ground to control the satellite operation and the bit rate is up to $4 \mathrm{kbps}$. So, need a $\mathrm{S}$ band uplink for receiving commands.

In this paper, receiver of satellite at $S$ band was developed, microwave modules of receiver were designed.

Block diagram of a receiver system was show in Figure 2. 


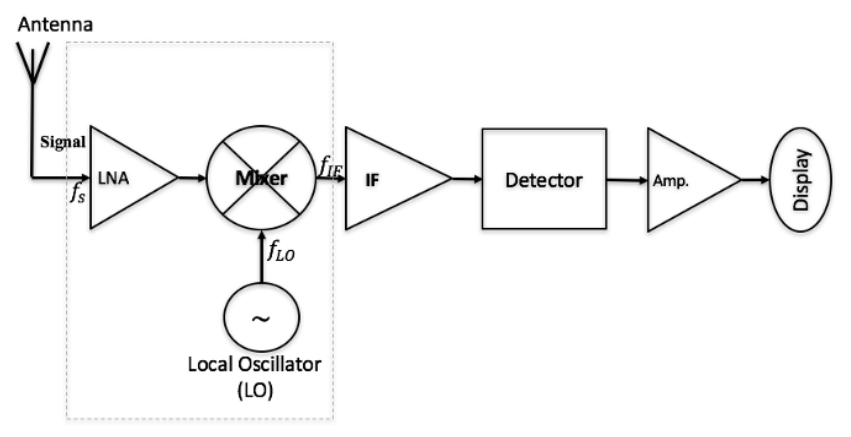

Figure 2. Block diagram of a receiver system

In the block diagram above, the receiving signals were received by antenna. Then being amplified to a desired amplitude level by the LNA. Output signal of LNA go to Mixer. At the mixer, output signal of LNA mix with signal of local oscillator (LO) become intermediate frequency (IF) signal.

There are previous works related to receiver of satellite/ ground station. Ground station work at VHF was designed and constructed at San Jose State University by M.Hunter Jeanine and E.Horton David [1], in which working at VHF, gain $5 \mathrm{~dB}$. A new $\mathrm{X}$ - band satellite groundstation for remote sensing applications by G.M.Quinn [2]. Low cost ground station design for nanosatellite missions by S.Tuli Tarun and G.Orr Nathan and E.Zee Robert [3]. These paper mentioned receivers of ground station at VHF. However, they only presented general information. It is difficult to understand for reader. Low noise amplifier of RF communication receiver was designed by Yu-na and Geng Li [4]. This LNA working frequency from $2.4 \mathrm{GHz}$ to $2.5 \mathrm{GHz}$, noise figure $0.8 \mathrm{~dB}$, gain $15 \mathrm{~dB}$, using PHEMT ATF54143. This design can only be properly applied for frequency below $2.5 \mathrm{GHz}$ and gain requirement not high. Almost previous paper, LNA design was simulated and done single measurement. It has not yet measured receiver's integrated microwave modules.

The purpose of design is to obtain the best result applied for NanoDragon satellite's receiver work in $\mathrm{S}$ band frequency. There are list results of design:

Low budget.

Compact and easy to integrate with system.

High gain.

Operate in wide range frequency.

Be responsive to requirements of receiver system.

\section{Design, Simulation and Fabrication: Low Noise Amplifier (LNA), Mixer}

\section{Low Noise Amplifier}

The low noise amplifier is a part of microwave modules of satellite's receiver. It amplifies microwave signal. The weak received signal from antenna go to LNA, was amplify amplitude.

The LNA network can only work efficiently once being impedance matched properly in both of its input and output. The purpose of impedance matching is to maximize the transferred power from the source to the load and minimized the reflected power from the load to the source, thus optimize the voltage standing wave ratio (VSWR). The Figure 3 below demonstrates a typical matching system, which includes input and output matching networks for LNA: 


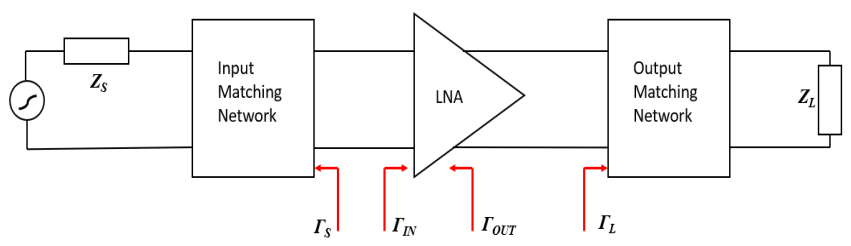

Figure 3. The diagram of amplifier stage [5].

When receiver operate at S band, LNA also operate at S band. In this case, the LNA works in the frequency range of $2 \mathrm{GHz}$ to $3 \mathrm{Ghz}$. According to the designing demand, the transistor type was used in this LNA is PHEMT SPF-2086 with low noise figure and high gain. Gain performance of SPF-2086 was shows in Figure 4.

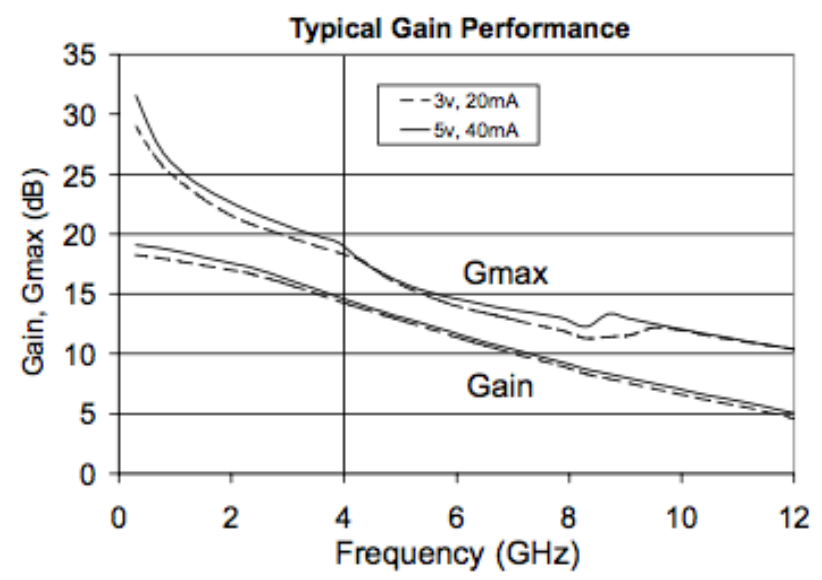

Figure 4. Gain performance of SPF-2086 [6].

Some methods are used to design LNA, such as: stubs, quarter - wave transformer, lumped components, ect. [7]. But in this design, quarter - wave transformer is better choice. Power supply for $\mathrm{SPF}-2086$ is $5 \mathrm{~V} / 40 \mathrm{~mA} . \mathrm{Z}_{\text {in }}, \mathrm{Z}_{\text {out }}$ were calculated:

$$
\begin{aligned}
& Z_{\text {in }}=Z_{0} *(2.136+j 2.199) \\
& Z_{\text {out }}=Z_{0} *(0.438+j 1.099)
\end{aligned}
$$

By using ADS software, using FR4 substrate, such as: permeability Mur $=1$, conductor thickness T $=0.035 \mathrm{~mm}$, dielectric constant $\mathrm{Er}=4.3$. LNA was designed schematic as Figure 5 .

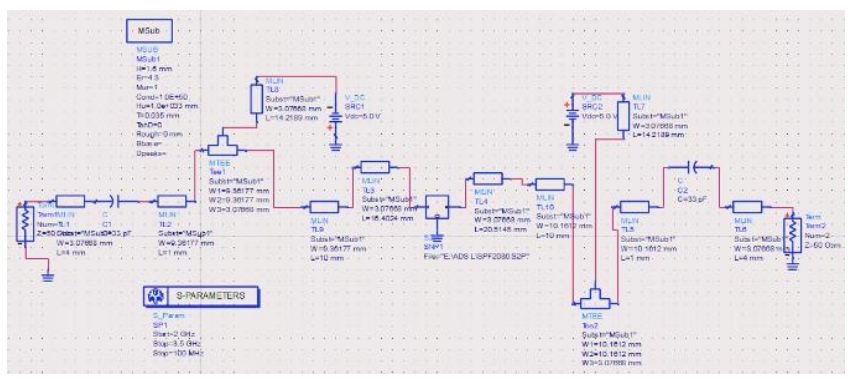

Figure 5. Schematic of LNA working $\mathrm{S}$ band. 
Simulation result of LNA was illustrated in Figure 6. The Figure below shows $S_{21}$ parameter and $S_{11}$ parameter. This LNA operate well in large range frequency and maximum gain $\left(\mathrm{S}_{21}\right)$ obtains $19.108 \mathrm{~dB}$, input reflection coefficient obtains $-12.3 \mathrm{~dB}$ at $2.9 \mathrm{GHz}$.
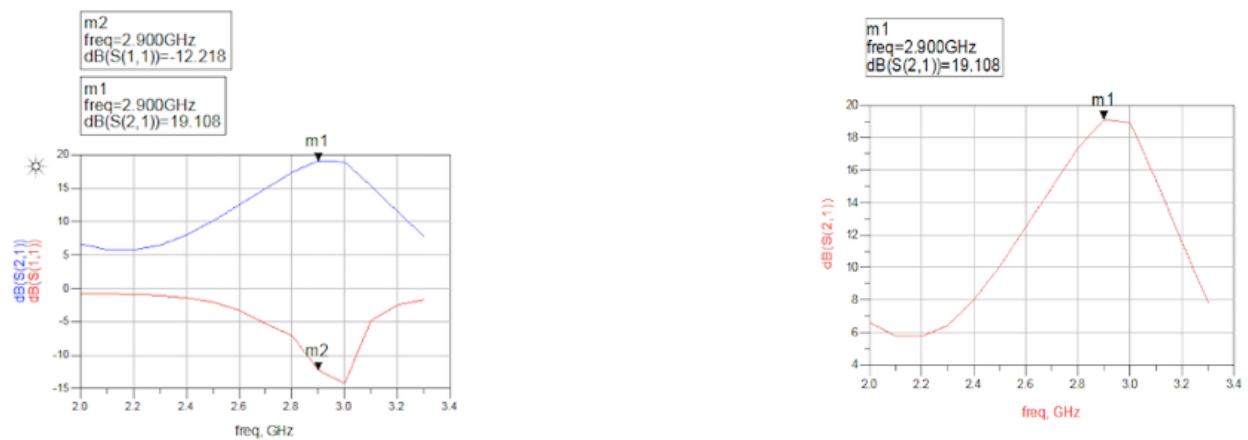

Figure 6. S parameter of LNA

See in in the Figure 6, LNA can amplified signal not only from $2 \mathrm{GHz}$ to $3.3 \mathrm{GHz}$ but also under 2 $\mathrm{GHz}$ and over $3.3 \mathrm{GHz}$. Maximum gain is $19.108 \mathrm{~dB}$ at $2.9 \mathrm{GHz}$. The input reflection coefficient, $\mathrm{S}_{11}$, is approximately $-12.3 \mathrm{~dB}$ at the desired frequency, which lies in the tolerance range.

We can integrate two stage LNA together. This 2-stage LNA have gain over $38 \mathrm{~dB}$. This result is suitable with requirement of NanoDragon Satellite.

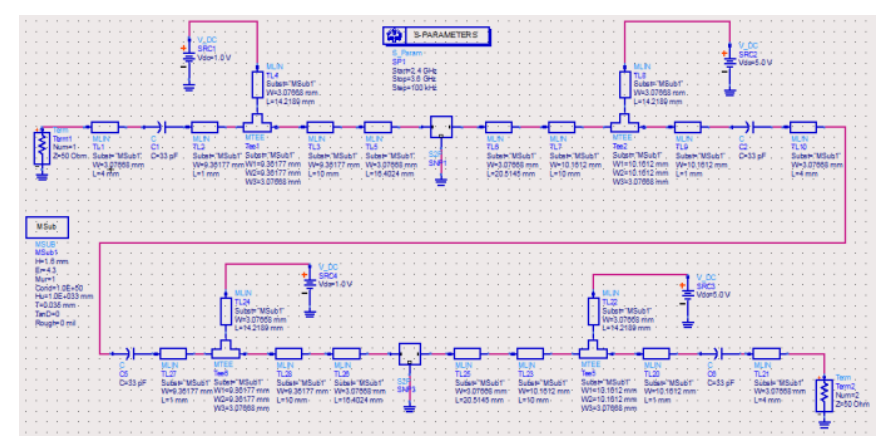

Figure 7. Schematic of 2 - stage LNA.

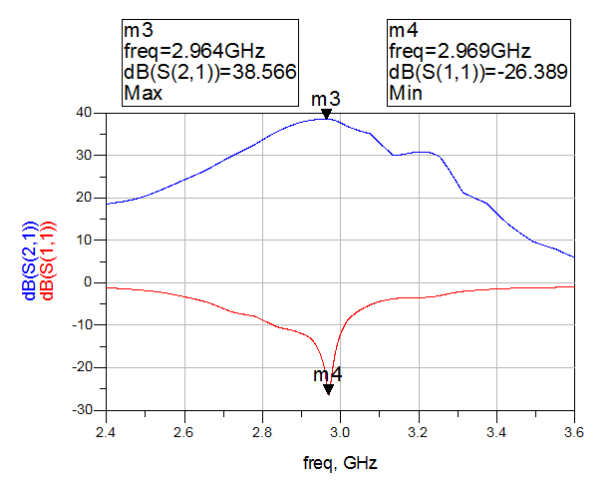

Figure 8. Result simulation of 2 - stage LNA. 
Schematic of 2 - stage LNA and result simulation of 2 - stage LNA were show in Figure 7 and Figure 8.

After simulation, schematic circuit converted into layout same in the Figure 9.

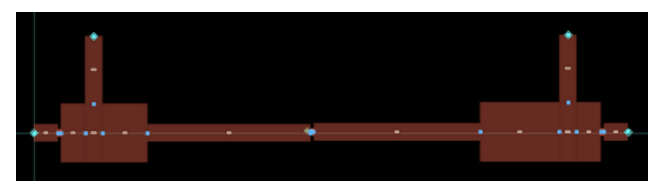

Figure 9. Layout of LNA circuit.

The manufactured LNA is shows in Figure 10.

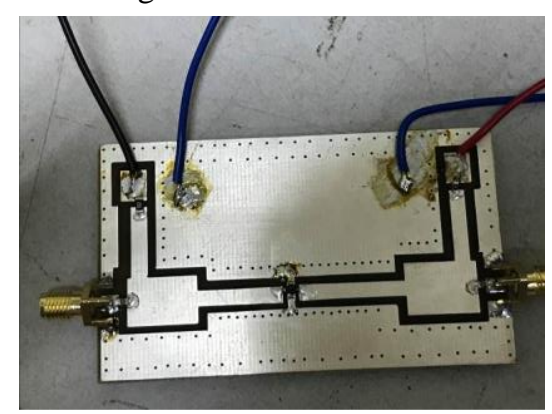

Figure 10. The fabricated LNA

Mixer

Mixer is three port device. In receiver system, its main function is to mix two input signal, its output is IF signal. The Figure 11 shows frequency conversion block.

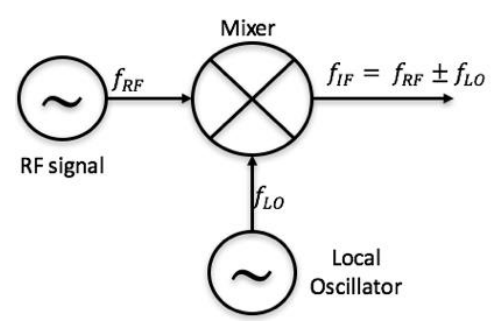

Figure 11. Mixer and frequency conversion [7].

Mixer is designed depend on microwave signal input and bandwidth requirement. In this case, Mixer used LT5527. Features of LT2257: have 16 pins; size $4 \mathrm{~mm}$ x $4 \mathrm{~mm}$; wide RF frequency rage is 400 MHz to $3.7 \mathrm{GHz}$; supply voltage range is $4.5 \mathrm{~V}$ to $5.25 \mathrm{~V}$. The Figure 12 shows block diagram of LT5527.

The radio frequency (RF) input is from $400 \mathrm{MHz}$ to $3.7 \mathrm{GHz}$ and the $\mathrm{LO}$ input is from $1.2 \mathrm{GHz}$ to $5 \mathrm{GHz}$. The RF and LO inputs are both single ended. The intermediate frequency (IF) output is differential. The IF output is matched and usable for IF frequencies of NanoSatellite's receiver.

Signal output of LNA go to LT5527 through single - ended $50 \Omega$ interfaces. Signal RF mixed LO signal by LT5527. Its output went IF stage and continue works. IF stage of this receiver required bandwidth is $100 \mathrm{MHz}$ to $120 \mathrm{MHz}$. RF signal input is $2.9 \mathrm{GHz}$.

The schematic of mixer was illustrated in Figure 13. 


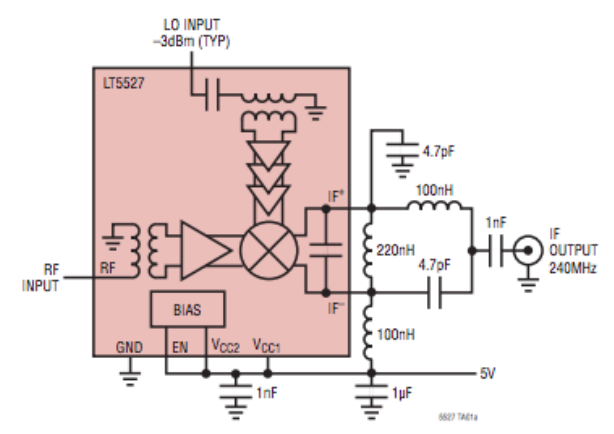

Figure 12. Block diagram of LT5527 [8].

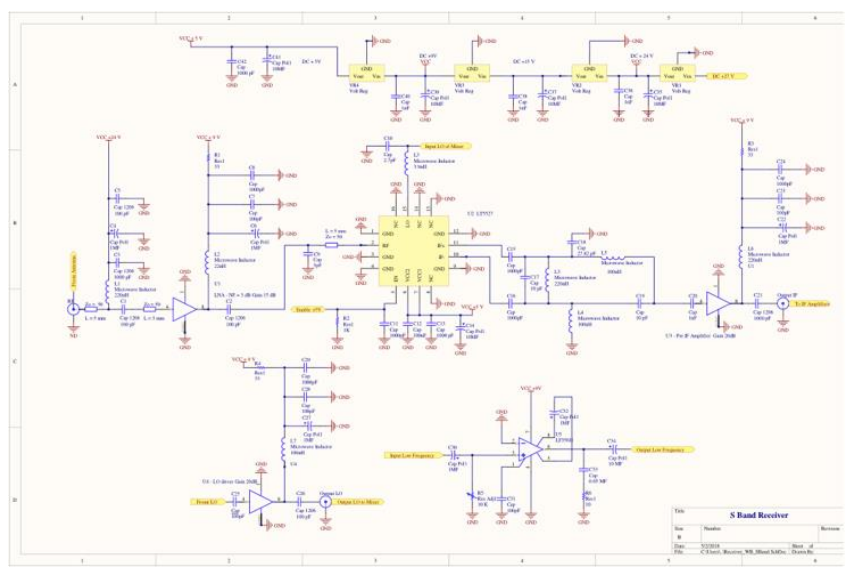

Figure 13. The schematic of Mixer

\section{Measurements Results}

The microwave modules of receiver were successfully fabricated by our group. By using Keysight (FielfFox MicroWave Analyzer N9917A $18 \mathrm{GHz}$ ), signal generator $8648 \mathrm{C}$ of Agilent and Test receiver ESPI and DC power supply, low noise amplifier, local oscillator and mixer were measured. Firstly, each item was measured. Then these items were integrated.

\section{LNA measurement}

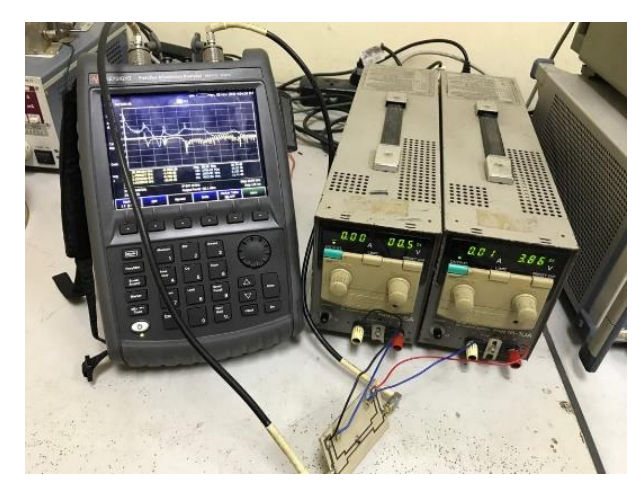

Figure 14. Set of LNA measurement. 


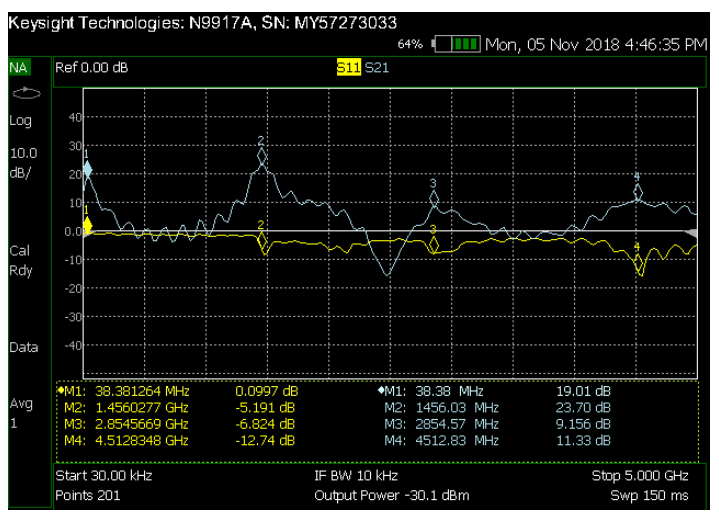

Figure 15. Measurement result.

See in Figure 15, 1 - stage LNA can amplify signal at wide frequency range, the maximum gain of $11.5 \mathrm{~dB}$ at $2.9 \mathrm{GHz}$. The comparison test result with simulation result proved to LNA operate well.

\section{LO measurement}

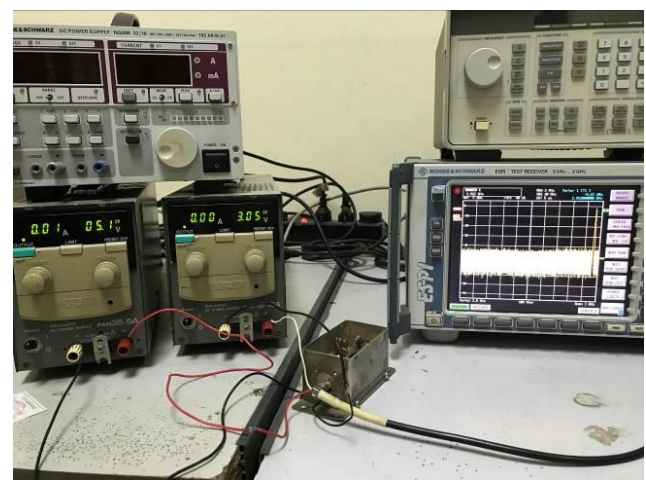

Figure 16. Set of LO measurement.

Testing LO was connected as Figure 16. Power supply for LO is $5 \mathrm{~V}$. In this paper, control signal is $0 \mathrm{~V}$ to $3.5 \mathrm{~V}$. Relationship between control power and frequency is linear. This linearity is measurement of LO in Figure 17.

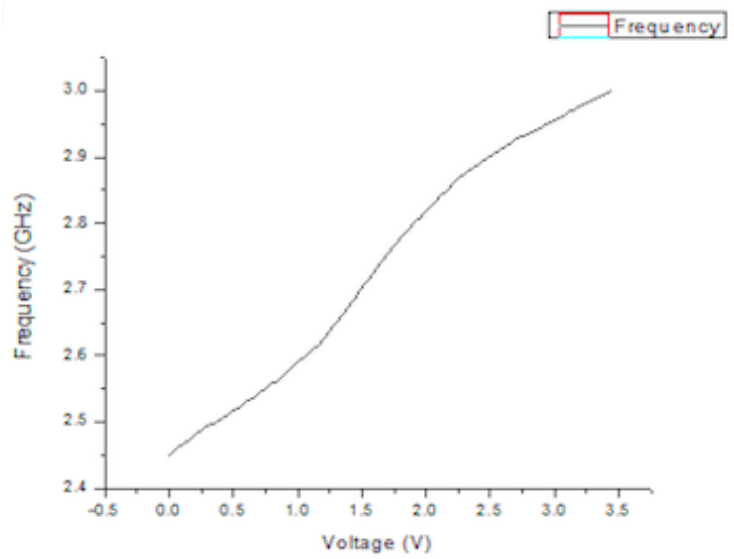

Figure 17. Measurement result of LO. 
See in figure above, this $\mathrm{LO}$ operate over $0 \mathrm{~V}$. Frequency is $2.45 \mathrm{GHz}$ at $0 \mathrm{~V}$. LO was measured from $2.45 \mathrm{GHz}$ to $3.1 \mathrm{GHz}$ because this receiver operated at $\mathrm{S}$ band, center on $2.9 \mathrm{GHz}$.

\section{Mixer measurement}

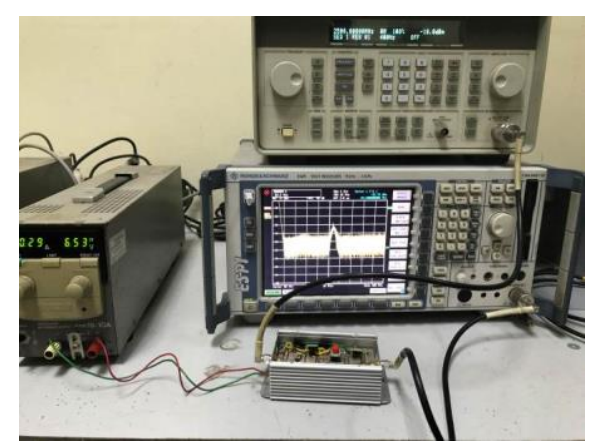

Figure 18. Setup mixer measurement.

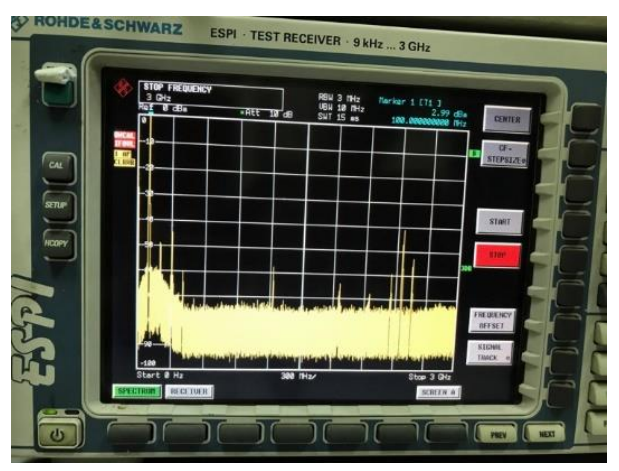

Figure 19. Measurement result of mixer.

See in the Figure 19, output of mixer is $100 \mathrm{MHz}$. This result is suitable for requirement of NanoSatellite.

\section{Integrated measurement}

RF stage of receiver consist of LNA, mixer and LO. These items were measured. Then they were integrated together. Set of integrated measurement was shows in Figure 20. Integrated measurement result demonstrated in Figure 21.

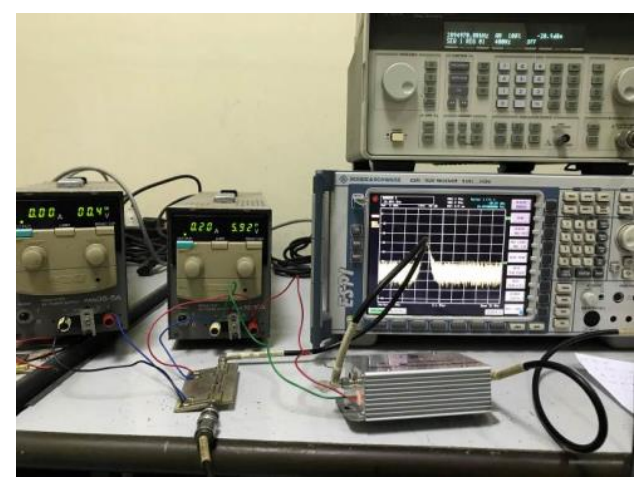

Figure 20. Set of integrated measurement. 


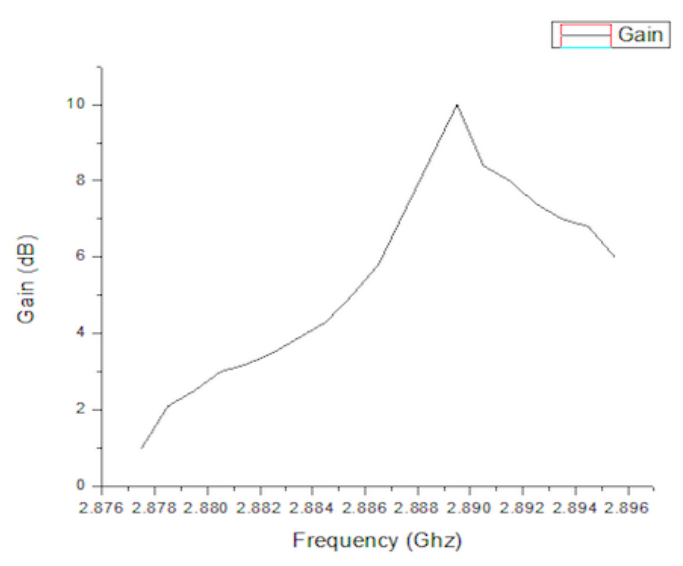

Figure 21. Integrated measurement result.

Integrated measurement result is good. Gain value is over $10.5 \mathrm{~dB}$

\section{Conclusion}

This paper introduced about receiver of ground station and satellite, focus on microwave modules of receiver. Low noise amplifier was designed, simulated and fabricated. At $2.9 \mathrm{GHz}$, simulation result of LNA is $19,1 \mathrm{~dB}$; measurement result of LNA is $11.5 \mathrm{~dB}$. After integrating LNA with frequency conversion, measurement integrate microwave modules result is $10.5 \mathrm{~dB}$. When integrating two stage LNA together have simulation result gain is over $38 \mathrm{~dB}$. With above result prove LNA operate well and can apply for Nanosatellite's receiver. Mixer was designed and measured. Input signal is microwave signal at $2.9 \mathrm{GHz}$. LO was designed and measured at frequency demanding. According to requirement of Nanosatellite, output intermediate frequency of mixer is $100 \mathrm{MHz}$. This result can respond to requirement. IF signal with bandwidth is suitable for demodulation BPSK of Nanosatellite's receiver.

\section{References}

[1] M.H. Jeaine, E.H. David, Design and Construction of a VHF Ground Station at San State University, Int.1.Engng Ed, 10 (5) (1994) 459-465.

[2] G.M. Quinn, A New X-Band satellite Ground Station for Remote Sensing Application, 2003 Australian International Aerospace Conference, (2003) 66-71.

[3] S.T. Tarun, G.O.Nathan, E.Z. Robert, Low cost ground station design for nanosatellite missions, 2006 AMSAT North American Space Symposium (2006) 128-132.

[4] Y. Na, G. Li, Design of a Low Noise Amplifier of RF Communication Receiver for Minc, 2012 IEEE Symposium on Electrical \& Electronics Engineering (2012) 80-85.

[5] T.V. Hoi, B.G. Duong, Study and design of wide band low noise amplifier operating at C band, VNU Journal of Mathematics - Physics 29 (2) ( 2013) 16-24.

[6] Sirenza Microdevices, SPF - 2086 Datasheet, https://www.datasheets360.com/part/detail/spf2086/3729919505518703085/

[7] D.M. Pozar, Microwave Engineering, $3^{\text {th }}$ Edition, John Wiley \& Sons, Inc- New York, United State of America, 2005.

[8] Linear Technology, LT5527 Datasheet, https://www.alldatasheet.com/datasheetpdf/pdf/262180/LINER/LT5527.html 